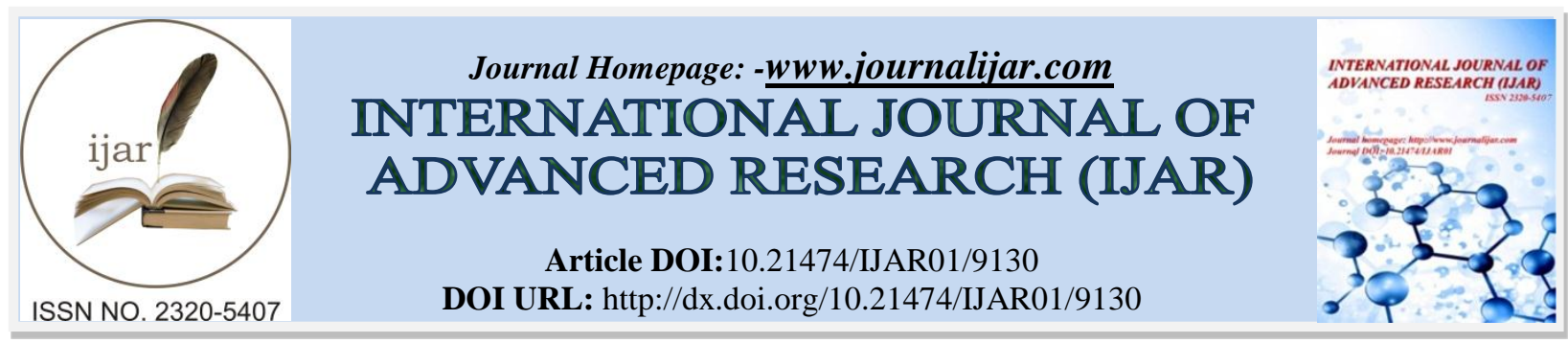

RESEARCH ARTICLE

\title{
MALIGNANT DEGENERATION IN SARCOMA OF A DERMATOFIBROSARCOMA OF DARIER FERRAND: A CASE STUDY.
}

\section{Mohamed Elmehdi Sahibi , Mouna Ejjiyar, Mehdi ElGueouatri ,Bhihi Abdelkoddous, Driss Elamrani And Yassine Benchamkha. \\ Department of Plastic and Reconstructive Surgery, Mohammed VI CHU, Marrakech.}

\section{Manuscript Info}

Manuscript History

Received: 24 March 2019

Final Accepted: 26 April 2019

Published: May 2019

Key words:-

Darier and Ferrand's

dermatofibrosarcoma , malignant

transformation fusocellular sarcoma.

\section{Abstract}

Darier and Ferrand dermatofibrosarcoma (DFS) is a cutaneous mesenchymal tumor of intermediate malignancy. It is a rare but not exceptional tumor, representing $0.1 \%$ of malignant skin tumors, slow growth, very high risk of local recurrence, but low metastatic potential. We report a case of malignant multi-recurrent degeneration in sarcoma of Darier Ferrand dermatofibrosarcoma in a 46 year-old patient, and this despite having evoked early diagnosis and performed a large surgical resection. This observation illustrates the frankly malignant but exceptional sarcomatous transformation.

Copy Right, IJAR, 2019,. All rights reserved.

\section{Introduction:-}

Darier and Ferrand dermatofibrosarcoma (DFS) is a rare but not exceptional malignant cutaneous mesenchymal tumor, accounting for $0.1 \%$ of malignant skin tumors and less than 5\% of adult soft tissue sarcomas [1-3]. It was described by Jean Darier and Marcel Ferrand in 1924 [4]. The preferred sites are the trunk, followed by the proximal part of the limbs and then the head and neck [3]. DFS often affects patients in their 3rd-4th decades with a slight male predominance and is clinically presented as a firm reddish plate or nodule $[5,6]$. Despite its distinct histological presentation, its histogenesis remains indefinite [3]. It is a so-called tumor with intermediate malignancy potential, good prognosis after complete resection, slow growth, very high risk of local recurrence, but low metastatic potential $[1,2,6,7]$. It is life-threatening in case of several recurrences. We report the case of a malignant degeneration of a Darier-Ferrand dermatofibrosarcoma of the back in high grade fusocellular sarcoma though the surgical excision initially was wide with $5 \mathrm{~cm}$ of lateral margins and carrying a healthy anatomical barrier in depth.

\section{Observation}

Ms. RT, aged 46, originally from and residing in south morocco, married housewife and mother of 5 children who had been operated for Total Thyroidectomy in 2013 (whose pathological result speaks of a multi nodular goiter without a sign of malignancy) under Livotyhirox 100ug / d . Moreover, she doesn’t present any other medical or surgical history .

The beginning of the symptomatology goes back to 3 years with the appearance of a nodular lesion on the level of the back (of $1 \mathrm{~cm}$ initially) increasing progressively of size $8 \mathrm{~cm} / 8 \mathrm{~cm}$, painful ulcero-budding resulting from pus and blood and a necrotic center (Fig 1) and evolving in a context of apyrexia and CEG.

Corresponding Author:-Mohamed Elmehdi Sahibi.

Address:-Department of Plastic and Reconstructive Surgery, Mohammed VI CHU, Marrakech. 
The patient benefited from a partial biopsy of the lesion on 30/01/2013 at the Dermatology Department of Mohamed VI University Hospital where the anatomopathological result showed a morphological and immunohistochemical appearance of a myxoid sarcoma that could suggest the diagnosis of Darier Ferrand dermatofibrosarcoma in its myxoid variant. Afterwards she was appointed in our formation where she has benefited from a wide excision with 5 $\mathrm{cm}$ of lateral margins (Fig 2) associated with an immediate thin skin graft (Fig 3) with a good healing (Fig 5).

One year later, in 12/02/2014, the patient arrived with a mobile mass at the upper limit of the previous grafted exeresis and she underwent excision of the lesion with anatomo-pathological study which showed a morphological aspect of a dermatofibrosarcoma.

The patient underwent excision with $5 \mathrm{~cm}$ lateral margins deepening part of the muscle and an anapath study that showed an appearance of high grade hemocerebrovascular fusocellular sarcoma with healthy lateral limits and a deep limit at $3 \mathrm{~mm}$.

On clinical examination the patient is hemodynamically and respiratory-stable, The skin around the loss of substance is thick, infiltrated with positive Chvostek sign, PDS of the back of $7 \mathrm{~cm} / 6 \mathrm{~cm}$ with a clean bleeding bud on contact (Fig 6) without any other associated lesions or palpable ADP. It is to be noted that a thoracoabdominopelvic CT scan was performed, which did not objectify a secondary localization.

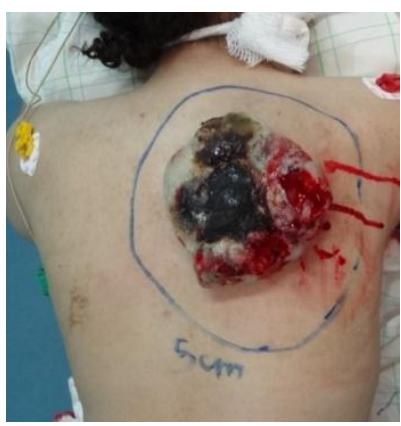

Fig 1:-ulcerative lesion of the back

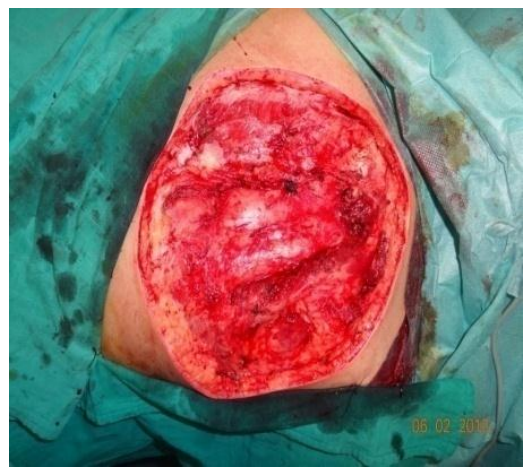

Fig 2:-wide excision carrying a healthy anatomical barrier in depth

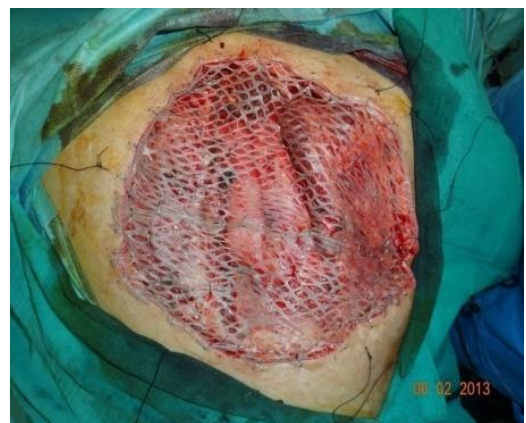

Fig 3:-thin skin graft immediate post operation 


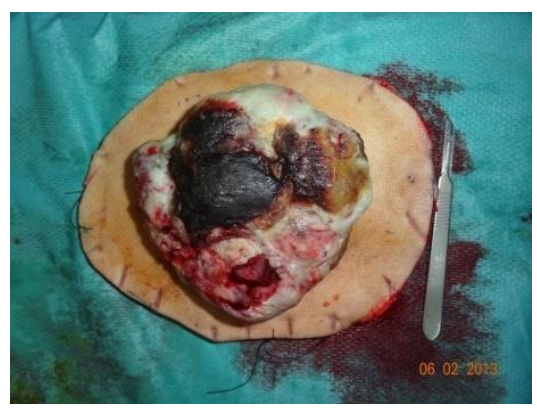

Fig 4:-Post operation area

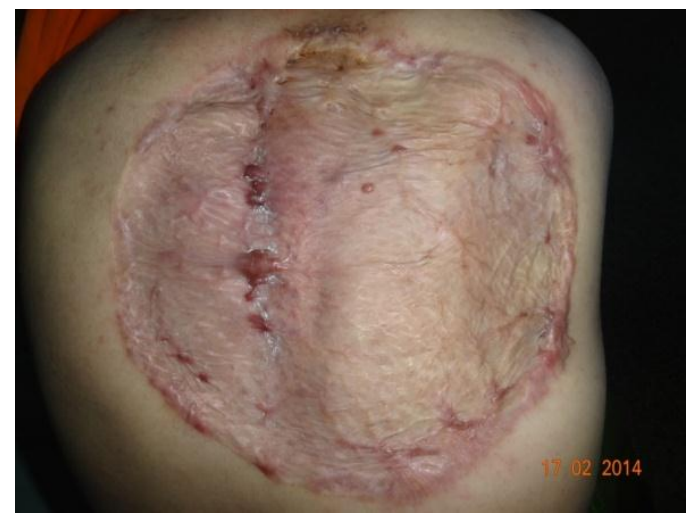

Fig 5:-Healing of the grafted area

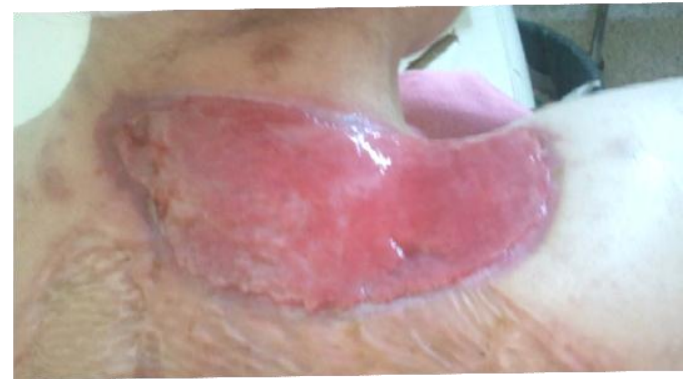

\section{Discussion:-}

Darier-Ferrand dermatofibrosarcoma is a dermal conjunctive tumor with spindle-shaped cells, more or less similar in its histological structure to sarcomatous tumors, but which is opposed to true primary fibrosarcomas by its still cutaneous origin, and by its very slow evolution. It has only exceptionally, and at a very late stage, a sarcomatous transformation that is frankly malignant metastatic $[9,8]$. This rare tumor represents between $0.1 \%$ and $1 \%$ of malignant skin tumors [9].

Dermatofibrosarcoma usually occurs in young adults between the ages of 20 and 40 [12]. and rarely in the elderly. Some cases have been reported in children and adolescents [13]. There is a very low male predominance.

Mandalenakis and Venne [14] and Soulie et al. [15] found a preferential localization on the anterior aspect of the trunk and the proximal extremities

Etiologically, some authors mention various factors exogenous in the occurrence of the disease such as parasitosis, angiomatous lesions, burn scars, vaccination, human bites, surgery, radiotherapy, traumatized nevi, syphilitic lesions, microtrauma on healthy skin, iatrogenic or occupational arsenical keratosis lesions $[9,16,11,18]$.

Other authors incriminate immunological causes such as annular chromosomes 22 which would cause an amplification of sequences of chromosomes 17 and 22 [16]. Minoletti et al. describe a monosomy 22 [17] while Diaz-Cascajo et al. suspect an intervention of the p53 protein in the pathogenesis of the disease [16]. 
Clinically, the lesion presents itself as an indurated plaque, covered with a skin of normal appearance and color, sometimes whitish, yellowish-white, pinkish, purplish or reddish, apparently well defined and mobile with respect to the deep planes. . At an advanced stage (nodular stage), the plate spreads, its surface becomes irregular and bumpy, realizing after a few months to a few years, a multinodular mass, often polychrome, of variable size, hard, perfectly mobile on the deep planes.

This evolution, in two stages, is not constant because certain forms are immediately uninodular or multinodular with secondary melting of the nodules. In the majority of cases, the lesion evolves slowly and gradually, with no functional signs or general disorders. The general state of the patients remains for a long time preserved explaining the long periods of consultation.

However, this tumor is often diagnosed after several recurrences. It has only exceptionally, and at a very late stage, a sarcomatous transformation that is frankly malignant metastasizing $[9,8]$.

In all cases, the diagnostic criteria are based on a bundle of arguments consisting of the evolutionary history of the tumor, the strict dermal site of the proliferation and the histological aspect of the tumor (fusiform cytological configuration, the swirling architecture, the hypervascular stroma and the perinervous castings). Immunohistochemistry, currently routine, often targets CD34 antigen positive labeling, but this marker is not specific $[9,17,18,8]$.

Surgery is the only therapeutic method that has proven effective in eradicating the tumor and preventing recurrence [19]. Exeresis must meet certain precise rules: monobloc resection with safety margins wide of 3 to $5 \mathrm{~cm}$ of healthy tissue, carrying a healthy barrier in depth. Indeed non-monobloc excisions may seed the operative site.

The Mohs technique requires the presence of a pathologist in the operating room to perform a thorough examination of the freshly grafted piece and the multiplication of immediate cuts, until obtaining sections without tumor cells, which contributes to considerable elongation.of operating time $[19,20]$.

Several teams using the Mohs technique with an extemporaneous examination showed that $3 \mathrm{~cm}$ margins were sufficient to remove all of the tumor cells. Others even proposed margins of excision at $2.5 \mathrm{~cm}$ and did not observe any recurrence [19].

Indeed, the frequency of recurrence is a function of the margins of excision: $70 \%$ for margins of $1 \mathrm{~cm}$, $40 \%$ for margins of $2 \mathrm{~cm}, 10$ to $20 \%$ for margins of $3 \mathrm{~cm}, 5 \%$ for margins of $4 \mathrm{~cm}$ and $1.75 \%$ of cases for margins of $5 \mathrm{~cm}$ [19]. The deep margin remains a topic of discussion because of the very definition of this margin, both anatomically and surgically.

Moreover, the tumor seems to be radiosensitive. Radiotherapy is used to complete the surgery in case of excision in the microscopic tumor zone, as well as palliative treatment [21].

Currently, oral imatinib, already used in the treatment of chronic myeloid leukemia and gastrointestinal stromal tumors, has been approved for the treatment of unresectable forms.

A French study, whose results were presented to ASCO [22], evaluated the use of this drug by neoadjuvant for two months to reduce the size of the tumor before its removal. A preoperative clinical response was obtained in $9 / 25$ cases $(36 \%)$. The interest of this approach to reduce margins during classical excisions remains to be demonstrated.

\section{Conclusion:-}

The tumor of Darier-Ferrand is characterized by its slow evolution, its diagnostic difficulty, its tendency to recur, the degeneration in fibrosarcoma possible after several recurrences.

Our observation illustrates the possibility of malignant degeneration in sarcoma (even if initial management was correct) of this rare tumor and the need to discuss the diagnosis early and perform a large surgical resection because the entire prognosis depends on it. . 


\section{Refernces:-}

1. Monnier D, Algros MP, MC Vidal, Danzon A, Pelletier F, et al. Dermatofibrosarcome protub érant (tumeur de Darier et Ferrand): Etude épidémiologique rétrospective descriptive en Franche-Comté sur une période de 20 ans (1982-2002). Ann Dermatol Venereol. 2005; 132(6-7)607. PubMed | Google Scholar

2. Joucdar S, Kismoune H, Boudjemia F, Acha D, Abed L. Les dermatofibrosarcomes de Darier et Ferrand: analyse r étrospective de 81 cas sur dix ans (1983-1994). Ann Chir Plast Esthét. 2001; 46(2):134-40. PubMed | Google Scholar

3. Stojadinovic A, Karpoff HM, Antonescu CR, Shah JP et al. Dermatofibrosarcoma Protuberans of the Head and Neck. Ann Surg Oncol. 2000; 7(9):696-704. PubMed | Google Scholar

4. Darier J, Ferrand M. Dermatofibromes progressifs et récidivants ou fibrosarcomes de la peau. Ann Dermatol Syph. 1924; 5:545-62. PubMed | Google Scholar

5. Morel M, Taïeb S, Penel N, Mortier L, Vanseymortier L, et al. Imaging of the most frequent superficial softtissue sarcomas. Skeletal Radiol. 2011; 40(3):271-284. PubMed | Google Scholar

6. Torreggiani WC, Al-Ismail K, Munk PL, Nicolaou S, et al. Dermatofibrosarcoma Protuberans MR Imaging Features. AJR. 2002; 178(4):989-993. PubMed | Google Scholar

7. Nedelcu I, Costache DO, Costache RS, Nedelcu D, et al. Darier- Ferrand Dermatofibrosarcoma Protuberans with Peculiar Aspect. BMMR. 2006; 9(1): 44-49. PubMed | Google Scholar

8. Transformation of Dermatofibrosarcoma Protuberans into a Fibrosarcoma

9. Mohamed Ali Sbai, Sofien Benzarti, Khaled Bouzaidi, Feten Sbei, Riadh Maalla Indian J Dermatol. 2016 JanFeb; 61(1): 121.

10. D. Lemm, L.O. Mügge, T. Mentzel, K. Höffken Current treatment options in dermatofibrosarcoma protuberance J Cancer Res Clin Oncol, 135 (2009), pp. 653-665 [Review]

11. R. Dagan, C.G. Morris, R.A. Zlotecki, M.T. Scarborough, W.M. Mendenhall Radiotherapy in the treatment of dermatofibrosarcoma protuberans Am J Clin Oncol, 28 (2005), pp. 537-539

12. D. Kérob, R. Porcher, O. Vérola, S. Dalle, E. Maubec, F. Aubin et al. Imatinib mesylate as a preoperative therapy in dermatofibrosarcoma: results of a multicenter phase II study on 25 patients Clin Cancer Res, 16 (2010), pp. 3288-3295

13. 4. Kasse A, Dieng M, Deme A, Fall MC, et al. Les dermatofibrosarcomes de darier et ferrand, à propos de 22 cas et revue de la littérature. Médecine d'Afrique Noire. 1999;46(4):222-27. [Google Scholar]

14. Dermatofibrosarcome de Darier-Ferrand de l'enfantDermatofibrosarcoma protuberans in a child is

15. Author links open overlay panelMSchollhammerMHGuilletBSassolasGGuillet

16. Dermatofibrosarcome de Darier-Ferrand: deux cas à localisation cervicofaciale J. Miloundja S. F. Assini Eyogho J. M. Mandji Lawson A. P. Makungu J. S. Bamba S. A. M. Nzenz A. Nziengui T. Ella Ondo L. N'zouba

17. Vulvar Darier-Ferrand dermatofibrosarcoma: Unusual localization of a rare tumour (about one case and a review of the literature) F. Mikou, M. Ennachit, F. Ouadirga A. Kazouini, M. El Karroumi, M. Ghazli, N. Matar Service de gynécologie obstétrique, France

18. Burkhard BR, Soule EH, Chahbra H, Postel A. Dermatofibrosarcoma protuberans: study of fifty six cases. Am J Surg. 1966 May;111(5):638-44. [PubMed] [Google Scholar]

19. Costa OG. Progressive reccurent dermatofibroma (Darier-Ferrand): anatomical study. Arch Derm Syph Paris. 1924;5:432-54. [PubMed] [Google Scholar]

20. 4. Kasse A, Dieng M, Deme A, Fall MC, et al. Les dermatofibrosarcomes de darier et ferrand, à propos de 22 cas et revue de la littérature. Médecine d'Afrique Noire. 1999;46(4):222-27.

21. Arnaud E, Perrault M, Revol M, Servant JM, Banzet P. Surgical treatment of Dermatofibrosarcoma Protuberans. Plast Reconstr Surg. 1997;100(4):884-995.

22. Pachet C. Faculté de médecine; 2007. Apport de la chirurgie micrographique dans la réduction des marges du dermatofibrosarcome de darier et ferrand: étude de 31 cas comparant l'exérèse large et la chirurgie micrographique

23. Haas RL, Keus RB, Loftus BM, Rutgers EJ, van Coevorden F, Bartelink H. The role of radiotherapy in the local management of dermatofibrosarcoma protuberans: Soft Tissue Tumours Working Group. Eur J Cancer. 1997 Jun;33(7):1055-60

24. Intérêt de l'imatinib dans le traitement des tumeurs de Darier-Ferrand C. Pages a, $\square, \quad$ P. Schneider a, D. Kerob a, M. Battistella a, M. Bagot a, P. May a, C. Le Maignan a, E. de Kerviler a, F. Pedeutour b, C. Vilmer a, C. Lebbé. 